\title{
Supporting Students by Maintaining Professional Well-Being in High-Stress Jobs
}

Melanie B. Blinder, Brandis M. Ansley, Kris Varjas, Gwendolyn T. Benson, and Susan L. Ogletree

\begin{abstract}
Student mental health, well-being, engagement, and deep learning is tied to teacher wellness. Georgia State University's Center for Research on School Safety, School Climate, and Classroom Management in partnership with The Collaboration and Resources for Encouraging and Supporting Transformations in Education project approached student health, wellness, and achievement by promoting change within teachers. Culturally specific professional development workshops were delivered to teachers, administrators, and other school staff. The workshops positively affected participants' health and wellbeing through activities focused on identifying the body's stress response and the development of personalized stress management plans to support healthy lifestyles.
\end{abstract}

\section{Supporting Students by Maintaining Professional Well-Being in High-Stress Jobs}

Research consistently links desirable student outcomes (e.g., academic, social, emotional, behavioral) with their learning environments (Cohen \& Geier, 2010; Greenberg, Brown, \& Abenavoli, 2016). Teachers and other school personnel cultivate healthy learning environments by: a) using effective instructional methods; b) managing student behaviors using positive behavior supports; and c) building and maintaining positive relationships with students (Haynes, 2014; Jennings \& Greenberg, 2009; Roorda, Koomen, Spilt, \& Oort, 2011). Students thrive in healthy learning environments; not only do they achieve their goals academically, but they also exhibit more prosocial behaviors and less manifestations of physical and mental health problems (Cohen \& Geier, 2010; Domitrovich et al., 2016; Jennings \& Greenberg, 2009). The energy and emphasis given to cultivating these ideal settings is well worth the effort for the sake of supporting students. Healthy learning environments, however, must begin with those in charge of creating and maintaining them.

Educators must sustain their own physical and mental well-being in order to set that tone for their students (Emery \& Vandenberg, 2010; Greenberg et al., 2016; Jennings \& Greenberg, 2009). Between lesson planning, paperwork, mandated testing, stringent evaluations, and addressing a myriad of student needs, teaching is a very demanding profession that requires great physical, mental, and emotional stamina (Ansley, Houchins, \& Varjas, 2016; Brunsting, Sreckovic, \& Lane, 2014; Emery \& Vandenberg, 2010; Greenberg et al., 2016; Pas, Bradshaw, \& Hershfeldt, 2012). Educator preparation programs do not typically address how they may cope effectively with the many stressors they encounter on the job 
(Emery \& Vandenberg, 2010; Montgomery \& Rupp, 2005). The Collaboration and Resources for Encouraging and Supporting Transformations in Education (CREST-Ed; http://crest.education.gsu.edu/) initiative at Georgia State University (GSU) recognized the need for stress management and effective coping skills in school personnel. As part of this U.S. DOE funded grant, the GSU Center for Research on School Safety, School Climate, and Classroom Management (The Center; http://schoolsafety.education.gsu.edu/) was contracted to address the professional development (PD) needs of teachers, administrators, and other school staff in schools.

\section{The Partnership}

The CREST-Ed Grant was developed to meet the challenges of preparing and retaining teachers for the specific demands of teaching critical subjects in high-needs schools in urban and rural localities. The CREST-Ed Grant was awarded to the GSU's College of Education \& Human Development by the U.S. Department of Education in the fall of 2014. GSU was one of 24 institutions nationwide to be awarded this competitive teacher quality partnership grant. Through CREST-Ed's focus on teacher preparation and retention, an emphasis was made to engage existing teachers, pre-service teachers, and other school professionals in collaborative professional development (PD) opportunities. These PDs are tailored to the specific needs of the partnering schools as articulated by the school leaders and community stakeholders involved.

The Center was originally included in the grant to facilitate PDs for CREST-Ed to meet the Grant's goal of teacher preparation and retention, specifically in the areas of bullying prevention and intervention. The team originally comprised the Center's director, who is also a professor in the Counseling and Psychological Services department at GSU, and a graduate student pursuing a Specialist in Education $(E d S)$ in School Psychology. The graduate student had been a teacher for 10 years before returning to graduate school. She was hired not only for her experience developing interactive and engaging presentations, but also because her teaching experiences gave her insight into the needs of school personnel.

Upon its initial work with CREST-Ed, The Center staff became aware of the need for mental health and wellness support for teachers in CREST-Ed partnered schools. In an early meeting of district coordinators, service providers, and university faculty associated with CREST-Ed, it was shared that 10 out of 11 participating schools expressed needs for stress management and wellness workshops for their staff. As the CREST-Ed schools and students are recognized as high needs, personnel working in the building sites are considered to be at a higher risk of burnout, and therefore, health problems, poor job performance, and attrition (Boyd et al., 2011; Torres, 2016). To meet these needs, the director of The Center hired a doctoral student in special education with past experience in clinical psychology and delivering stress management workshops. As part of The U.S. Department of Education's Office of Special Education Program and doctoral level training grant entitled Project LEADERS (Leaders in Exceptionalities Alternative and Delinquency-related Environments through Research and Scholarship) at GSU, this advanced doctoral student had conducted research related to best practices regarding interventions that were effective with youth thought to be at-risk of school failure in alternative education settings. 
Her research focus addressed such interventions by addressing the mental health and wellness needs of teachers and other school personnel and had resulted in the opportunity to publish a research-to-practice article (Ansley et al., 2016) and participate in a podcast about her published work (http://www.pubs.cec.sped.org/podcast-optimizing-special-educator-wellness-and-job-performance-throughstress-management/). This advanced doctoral student's experience was made further relevant by her eight years of teaching experience in high-need schools. With the addition of the third team member, The Center's CREST-Ed team began developing and providing PDs for partnered schools to include her areas of expertise.

\section{Professional Development for School Personnel Wellness and Stress Management}

The Center's CREST-Ed team was able to collaborate with participating schools and delivered PDs focused on teacher wellness, self-care, and stress management strategies. The Center's team approached the task of working with schools from a culturally specific, needs-based design. These partnerships were founded in reciprocal phases of needs-based inquiry and hosting school feedback. These efforts helped to establish relationships between the professional development facilitators and the hosting school's stakeholders to ensure meaningful experiences for all participants. In a distinctive approach to creating professional development seminars and workshops, The Center's CREST-Ed team did not deliver premade and formerly developed presentations to hosting schools. Rather, school, culture, and contextspecific presentations were developed for the particular needs of the school personnel who were receiving the training. The presentations were guided by input from school administrators and other staff members in an iterative process with respect to the valuable information the school personnel had to share with the professional development facilitators to address local and contextual issues (Nastasi, Varjas, Bernstein, \& Jayasena, 2000; Nastasi, Moore, \& Varjas, 2004). Although varied in the makeup of their staff, the age of students taught (elementary and secondary), and the unique challenges for their community, school stakeholders continually shared the same needs for their staff: help with selfcare and stress management. These schools asked the facilitators from The Center to develop presentations to deliver information about personal wellness, de-escalation, and stress management techniques and strategies for teachers as well as students.

\section{Culturally Relevant Practices}

The Center's CREST-Ed team took a culturally specific approach to the partnerships in order to make the work The Center engaged in with the teachers at the participating schools relevant. Similar to the phases of Participatory Culture-Specific Consultation (PCSC; Nastasi et al., 2000), The Center's team has approached its partnership with CREST-Ed schools with a systematic method to developing and delivering professional developments. PCSC is a "nonlinear and recursive process" (Nastasi et al., 2000 p. 404) where facilitators and stakeholders are engaged in active discussion and reflection throughout the consultation process. As such, the team has met with stakeholders at each school prior to every PD delivered to ensure that the specific needs of that community were met by the team. 
As with PCSC, the initial phases of partnerships began with learning the culture of the participating schools and forming partnerships. Unlike many PDs brought to schools from outside contributors, there have been no canned programs or presentations delivered to schools or other audiences by The Center's CREST-Ed team. Work in the schools is an ever-changing and evolving partnership between The Center and the identified schools. The work done by The Center's team is consistent with multi-tiered systems of support where focus has been placed on universal supports for the teachers and staff members at the schools, as well as to more specific groups of school professionals who have been identified as needing more focused intervention and support from The Center's staff. Furthermore, the stress management and wellness presentations that have been delivered to the schools are not developed for a particular academic content area. The information is presented in ways which are applicable to teachers regardless of subject area taught, or age of students in the classroom, and has been delivered to teachers at all levels of education: elementary, middle, and high school staff, as well as to pre-service teachers in both undergraduate and graduate programs. When given the opportunity to present information in novel contexts, such as through webinars, The Center staff further adjusts their content delivery and the resources provided.

\section{PD Materials and Activities}

To date, the Center's CREST-Ed team has delivered stress-management focused PDs to over 400 school professionals. The Center's team has created a Three-Tiered Model for Educator Stress Management (see Appendix A) based on research (e.g., Greenberg et al., 2016) that links self-care to optimal wellness and job performance, which ultimately affects their job satisfaction, school climate, and student outcomes. At the foundation of stress-management is self-care. Self-care behaviors promote wellness as well as the ability to perform on the job and build positive relationships with others. These positive relationships are not only requisite to effective instruction and behavior management, but personal connections also make a difference during tense moments that require de-escalation. Thus, the core focus of The Center's presentations are often on self-care and tied to the learning environment with the idea that the educator's wellness must come first.

Workshops were most often structured by a Self-Directed Stress Management Plan (SSMP; see Appendix B). The original version of the SSMP (Ansley et al., 2016) was developed for special educators to illustrate how personalized stress management plans can be written and implemented in a similar way to that of students' Individual Education Plans (IEPs), a process with which they are familiar. It was intended to guide educators while allowing flexibility to include preferred coping strategies. The original SSMP accompanied an article that described evidence-based strategies that reduce stress-related symptoms (Ansley et al., 2016). Since then, the SSMP was modified (SSMP 2.0) to meet the contextual need of a Council for Exceptional Children (CEC) PD webinar (http://www.pubs.cec.sped.org/web1701a/). This version was designed to facilitate participants' engagement in a guided and scaffolded interaction with the resource. The SSMP 2.0 also included components specific to the school day (workplace relationships, communications, and de-escalation), whereas the original SSMP mostly focused on self-care outside the job, under the premise that better coping skills would also improve the 
quality of their work experiences. While self-care remains the core of the PDs, the team from The Center also sought to demonstrate how effective self-care and coping also applied directly to the school setting. The most recent version, the SSMP 3.0, was developed to help engage workshop attendees in their own individualized stress management plan. It more closely resembles the SSMP 2.0, with additional examples of positive work-related communications listed in the guide.

Facilitators began workshops, not only with an explanation of their professional backgrounds, to build creditability with attendees, but they also made themselves vulnerable by disclosing their own experiences with educator stress. By doing so, The Center's team encouraged the audience to explore their own experiences and motivations to manage their own stress. From there, the workshops moved into the identification and recognition of stress, the natural physiological and psychological reactions to stress, and science-backed ways to go about managing stress. Presenters have utilized multiple modalities to deliver content. Facilitators have used interactive technology, such as Padlet (www.padlet.com), to engage participants in meaningful discussion, small groups and corporative learning groups which utilize strategies such as jigsaw learning, didactic instruction, experiential learning through discussions of vignettes describing examples of teachers experiencing burnout, and many opportunities for reflective practices.

\section{Participant Feedback and the Iterative Process}

The effectiveness of the PDs ultimately is determined by the attendees. No matter how well organized or scientifically based, the content must have meaning and be useful to participants if it is going to be effective. The Center's team used a combination of verbal feedback and surveys from CREST-Ed leaders, school administrators, and attendees to help refine workshops. This is much of why each version of the SSMP has become more specific as subsequent PDs have been delivered to new audiences. While the original version emphasized a variety of stress management strategies, the latest SSMP has focused on ways to apply mindfulness to one's personal life as well as his or her learning environment. Mindfulnessbased interventions have the most empirical research support among school-based stress-reduction studies (Ansley, Houchins, \& Varjas, 2017; Greenberg et al., 2016). In addition, mindfulness requires less time commitment and financial investment in comparison to other stress-reduction methods. This was of paramount importance, as many educators constantly reported a lack of time and monetary resources for self-care as barriers to their engagement in these practices. The increased focus on mindfulness in the later versions of the SSMP helped address such obstacles.

\section{Successes and Otherwise}

The Center's team has received positive feedback regarding attendees' interest in their own self-care. After most workshops, the facilitators have been contacted by participants with requests for resources. In some cases, school administrators have requested additional sessions from The Center. For one school in particular, the Center has made multiple appearances and delivered presentations specific to building positive relationships, classroom management, de-escalation training, and creating safe spaces. 
The team's efforts have certainly been met with challenges as well. There were instances when the facilitators were asked to present to teachers who were unaware that they would be missing their planning period; a rather stressful way to start a mindfulness and stress management workshop. At other times, the facilitators presented to a faculty of 40-plus participants where the air-conditioning stopped running minutes into the presentation. A crowded room with no air-conditioning in Georgia in the month of May could be compared to a slow cooker, the temperature creating a system of pressure which gradually cooks the inhabitants. Additionally, the demeanor of some of the participants who were required to attend (e.g., faculty meeting, workshops during planning periods) was often different from presentations where they chose to attend (e.g., conference workshops, concurrent session options). Some participants who were required to attend openly expressed their disdain with having to be there. The facilitators generally respond with compassion (e.g., "I know you're all super busy, and we appreciate that you're here," "We can remember frustrations of losing some of our planning time." "There's no tired like teacher tired."). The best-case scenario was when those most reluctant actually turned out to be the most active participants. Facilitators were able to engage participants by giving them real-world examples of mindful practice in schools where students are similar to their own, being open with their own experiences of mindful practices and mismanaged stress, and by being empathetic to the teachers' concerns. In an I-wouldn't-have-believed-it-if-I-hadn't-seen-it-for-myself-moment, participants attending a professional development on finishing the school year strong and preparing students for stress related to upcoming high-stakes testing, teachers were visibly shocked and impressed when they viewed a video of students practicing mindful meditations in the classroom as a regular part of the school day and even more so as a redirection strategy for students who had participated in a physical altercation with one another. Other times, forced participants have been off-task and engaged in other activities (e.g., on their personal computers or other electronic devices). While the workshops involved frequent interaction, facilitators respected each attendee's choice to determine their level of participation. Based on observation, mandatory attendees appeared more enthusiastic about the PDs when they were given advance notice and expected the workshops. The most resistance, as indicated by nonverbal gestures or disengagement, appeared most often when attendees were not made aware of the PDs and instructed without notice to drop what they were doing and report to the workshop.

\section{Future Directions}

The Center for Research on School Safety, School Climate, and Classroom Management continues its work in supporting teacher health and wellness and affecting student achievement by developing and delivering lectures, seminars, trainings, and webinars on the subject of teacher health and wellness. Student engagement and deep learning cannot happen in an educational system that does not take care of its educators. Teacher well-being is a crucial piece to the puzzle which is student achievement. By engaging in activities which help teachers learn how to recognize and manage their stress, they are better able to manage and serve their students. 


\section{Acknowledgments and Grant Information}

The authors disclosed receipt of the following financial support for the research and/or authorship of this article. Funding for this research was provided by the U.S. Department of Education through the following grants awarded to Georgia State University: 1) CREST-Ed (Collaboration and Resources for Encouraging and Supporting Transformations in Education, PR Award Number U336S140036); and 2) Project LEADERS (Leaders in Exceptionalities Alternative and Delinquency-related Environments through Research and Scholarship, PR Award Number H325D110030). The contents of this report do not necessarily represent the policy of the Department of Education or endorsement by the federal government.

\section{References}

Ansley, B. M., Houchins, D., \& Varjas, K. (2016). Optimizing special educator wellness and job performance through stress management. Teaching Exceptional Children, 48(4), 176. doi:10.1177/0040059915626128

Ansley, B., Houchins, D., \& Varjas, K. (2017, April). Stress management interventions and PK-12 Teachers: A systematic review of studies. Poster presented at the annual conference for the Council for Exceptional Children, Boston, MA.

Boyd, D., Grossman, R., Ing, M., Lankford, H., Loeb, S., \& Wyckoff, J. (2011). The influence of school administrators on teacher retention decisions. American Educational Research Journal, 48(2), 303-333.

Brunsting, N. C., Sreckovic, M. A., \& Lane, K. L. (2014). Special education teacher burnout: A synthesis of research from 1979 to 2013. Education and Treatment of Children, 37(4), 681-711.

doi:10.1353/etc.2014.0032

Cohen, J., \& Geier, V. K. (2010). School climate research summary: January 2010. Retrieved from http://www.schoolclimate.org/climate/schoolclimatebriefs.php

Domitrovich, C. E., Bradshaw, C. P., Berg, J. K., Pas, E. T., Becker, K. D., Musci, R., et al. (2016). How do school-based prevention programs impact teachers? Findings from a randomized trial of an integrated classroom management and social-emotional program. Prevention Science, 17(3), 325-337. doi:10.1007/s11121-015-0618-z

Emery, D. W., \& Vandenberg, B. (2010). Special education teacher burnout and ACT. International Journal of Special Education, 25(3), 119-131.

Greenberg, M. T., Brown J. L., \& Abenavoli, R.M. (2016). Teacher stress and health effects on teachers, students, and schools. State College, PA: Pennsylvania State University, Edna Bennett Pierce Prevention Research Center.

Haynes, M. (2014). On the path to equity: Improving the effectiveness of beginning teachers. Washington, DC: Alliance for Excellent Education.

Jennings, P. A., \& Greenberg, M. T. (2009). The prosocial classroom: Teacher social and emotional competence in relation to student and classroom outcomes. Review of Educational Research, 79(1), 491525. 
Montgomery, C., \& Rupp, A. (2005). A meta-analysis for exploring the diverse causes and effects of stress in teachers. Canadian Journal of Education, 28(3), 458-486. http://dx.doi.org/10.2307/4126479

Nastasi, B. K., Moore, R. B., \& Varjas, K. (2004). School-based mental health services: Creating comprehensive and culturally specific programs. Washington, DC: American Psychological Association.

Nastasi, B. K. Varjas, K., Bernstein, R., \& Jayasena, A. (2000). Conducting participatory culture-specific consultation: A global perspective on multicultural consultation. School Psychology Review, 29, 401413.

Pas, E. T., Bradshaw, C. P., \& Hershfeldt, P. A. (2012). Teacher- and school-level predictors of teacher efficacy and burnout: Identifying potential areas for support. Journal of School Psychology, 50, 129-145. http://dx.doi.org/ 10.1016/j.jsp.2011.07.003

Roorda, D. L., Koomen, H. M., Spilt, J. L., \& Oort, F. J. (2011). The influence of affective teacher-student relationships on students' school engagement and achievement a meta-analytic approach. Review of Educational Research, 81(4), 493-529.

Torres, A. T. (2016). How principals influence relational trust and teacher turnover in no excuses charter schools. Journal of School Leadership, 26(1), 61-91.

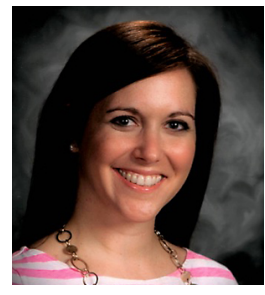

Melanie B. Blinder was a public school teacher for 10 years in an elementary setting before she left the classroom to pursue advanced studies in School Psychology. Ms. Blinder is passionate about the art of teaching, fostering engaging and challenging learning environments, and building student-teacher relationships. Currently, Ms. Blinder helps facilitates professional development workshops on these topics.

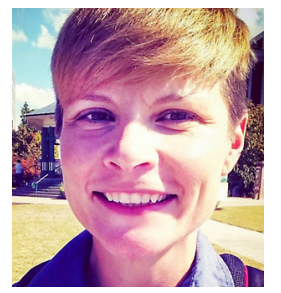

Brandis M. Ansley is a U.S. DOE Office of Special Education (OSEP) doctoral fellow in her fourth year at Georgia State University. Her combined professional experiences include more than 15 years as a special educator and mental health practitioner. She is the primary author of a research-to-practice paper published in TEACHING Exceptional Children in March 2016 that details ways special educators can design and implement their own stress management plans.

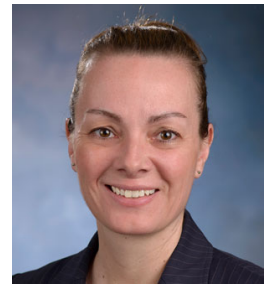

Kris Varjas is a Professor in School Psychology and the director of The Center for Research on School Safety, School Climate, and Classroom Management at Georgia State University. Dr. Varjas' primary areas of interest include a wide variety of issues: bullying, school safety and school climate, and mental health prevention and intervention. 


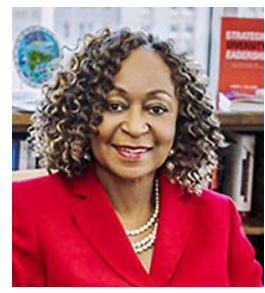

Gwendolyn Benson is the Associate Dean for school, community and international partnerships in the College of Education \& Human Development at GSU. She currently serves as the principal investigator for the Network for Enhancing Teacher Quality (NET-Q), a collection of projects funded by a $\$ 13.5$ million Teacher Quality Partnership grant from the U.S. Department of Education designed to prepare teachers for the demands of teaching high-need subjects in high-need schools. She also works to sustain the CEHD's professional development school network, facilitates international outreach and partnerships, and works closely with the Alonzo A. Crim Center for Urban Educational Excellence.

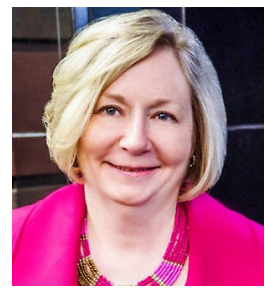

Susan Ogletree is the Director of the Center for Evaluation and Research in the College of Education \& Human Development at Georgia State University. In her job as Director, her office is responsible for overseeing $\$ 17,000,000$ in external funding for national and international programs. She also works with faculty to identify potential partners for both national and international grant initiatives. 
Appendix A

The Center's Three-Tiered Model for Educator Stress Management

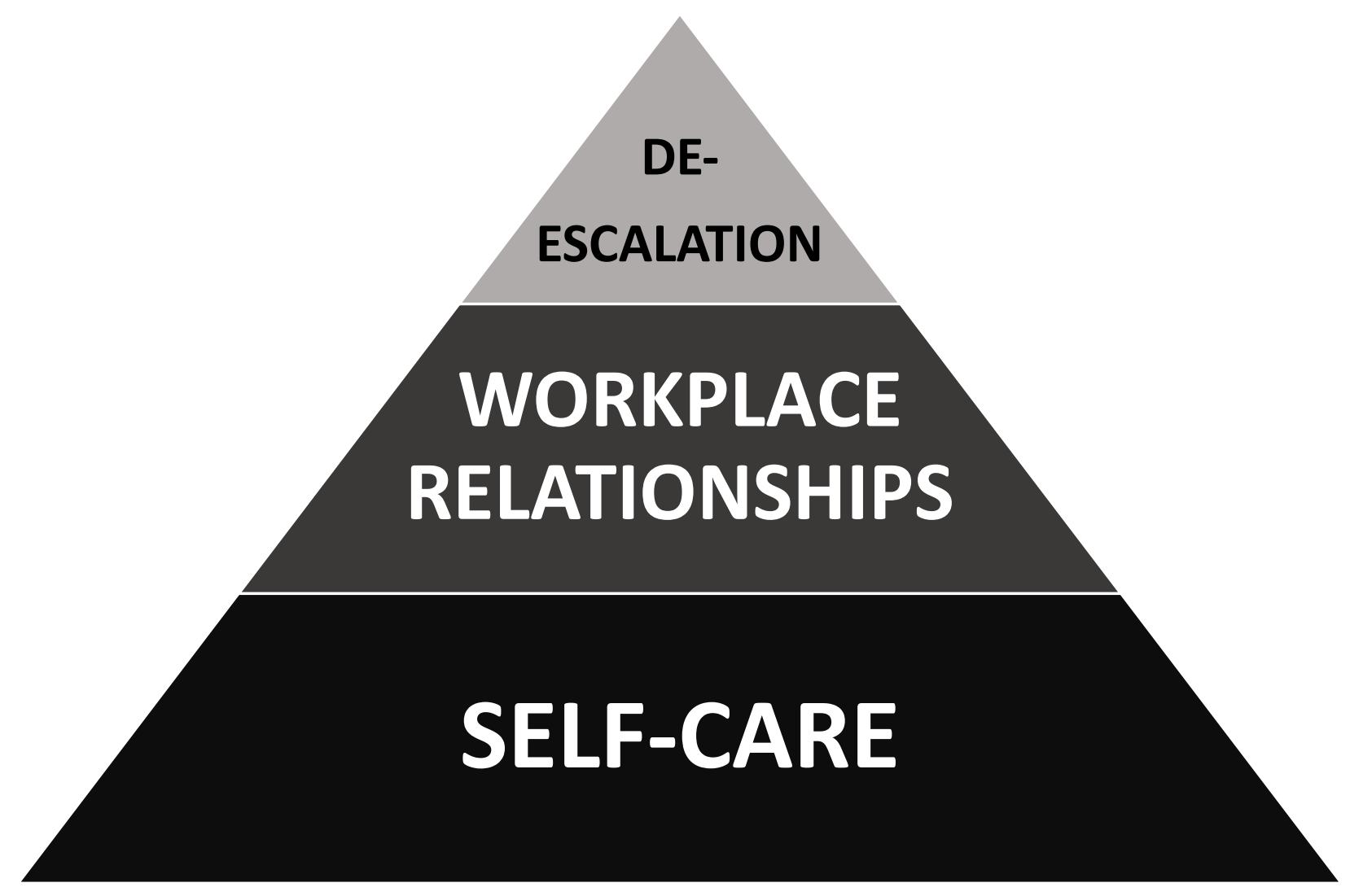




\section{Appendix B}

\section{Guide to Self-Directed Stress Management Plan 3.0}

1. Why manage YOUR stress? How can you benefit from effective coping skills?

2. Identify your signs of burnout and risk for stress-related symptoms. What happens with you, physically and/or mentally, when your stress levels have reached a critical point?

high blood pressure indigestion/heartburn relationship problems dread/pessimism weight gain or loss increased heart rate problems sleeping increased fear/worry lack of mental focus upset stomach chronic aches and pains irritability/sadness/mood changes lack of patience/tolerance tense/feel you cannot relax more simple errors than usual

3. Basic self-care

3a. Nutrition. List one target behavior that will improve your nutrition as it pertains to your quality of life. What will you change? How? When?

(e.g., I will consume 64 ounces, or four small bottles, of water each day. I will have my first sip of water before I get started with my day.)

3b. Exercise or Movement. List one target behavior that will keep you physically fit or at least get you started.

(e.g., I will park from the furthest space out. When I have no more than two floors up or down to go, I will take stairs, not elevator.)

3c. Other basic self-care. List one additional target behavior that will improve your quality of life. This may be related to your sleep, social, or other basic wellness-related habits. (e.g., On school/work nights, I will stop all activities and begin a wind-down routine at $10 \mathrm{pm}$.) 


\section{Mindful habits}

4a. Commit to a time, place, and routine for mindfulness training/reflection/meditation. (e.g., For 10 minutes, before I leave for work, Monday through Friday; For 20 minutes, at 10:40 pm each school night, so I can fall asleep by $11 \mathrm{pm}$ ).

I will engage in mindfulness training for minutes, at (time), on the following

days:

Types of evidence-based training I am willing to try: progressive muscle relaxation (PMR) yoga body scan mindful breathing guided imagery

4b. Habits of mind. Consider your ability to take action as needed while letting go of worries or unproductive thoughts that only burden you.

\begin{tabular}{|c|l|}
\hline $\begin{array}{c}\text { BURDENS \& WORRIES BEYOND MY } \\
\text { CONTROL }\end{array}$ & \multicolumn{1}{c|}{ WHAT I CAN CONTROL } \\
$\begin{array}{c}\text { (e.g., Attitudes of my co-workers, things } \\
\text { people say behind my back, what my } \\
\text { students do outside of school) }\end{array}$ & $\begin{array}{l}\text { education, the way I treat others, the } \\
\text { way I treat myself, the people I allow into } \\
\text { my "mental space") }\end{array}$ \\
\hline & \\
& \\
& \\
&
\end{tabular}


4c. Other mindspace "consumables." Consider what you will consume with your mindspace, for your own well-being.

\begin{tabular}{|l|l|}
\hline \multicolumn{1}{|c|}{ LESS } & \multicolumn{1}{c|}{ MORE } \\
$\begin{array}{l}\text { (e.g., news, nerve "rattling" } \\
\text { documentaries, fear-mongering, gossip, } \\
\text { drama-filled relationships, tending to every } \\
\text { notification on my phone) }\end{array}$ & $\begin{array}{l}\text { (e.g., inspirational/spiritual podcasts, } \\
\text { supportive connections with others } \\
\text { [humans and animals], soothing music, } \\
\text { nature, coloring, arts/crafts, cooking, } \\
\text { gardening) }\end{array}$ \\
\hline & \\
& \\
& \\
\end{tabular}

5. Interpersonal Relationships at Work

Tips for promoting positive workplace relationships

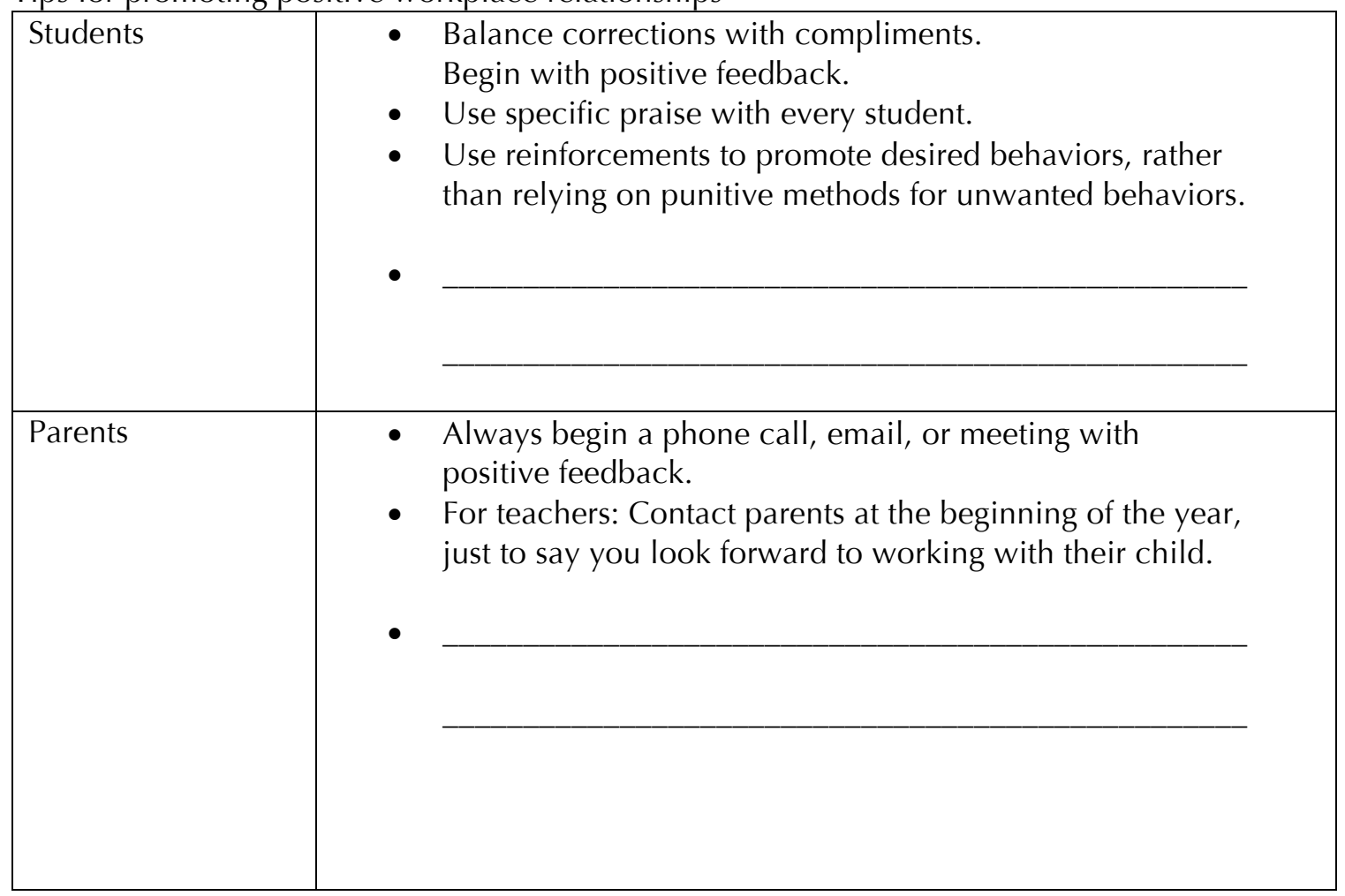




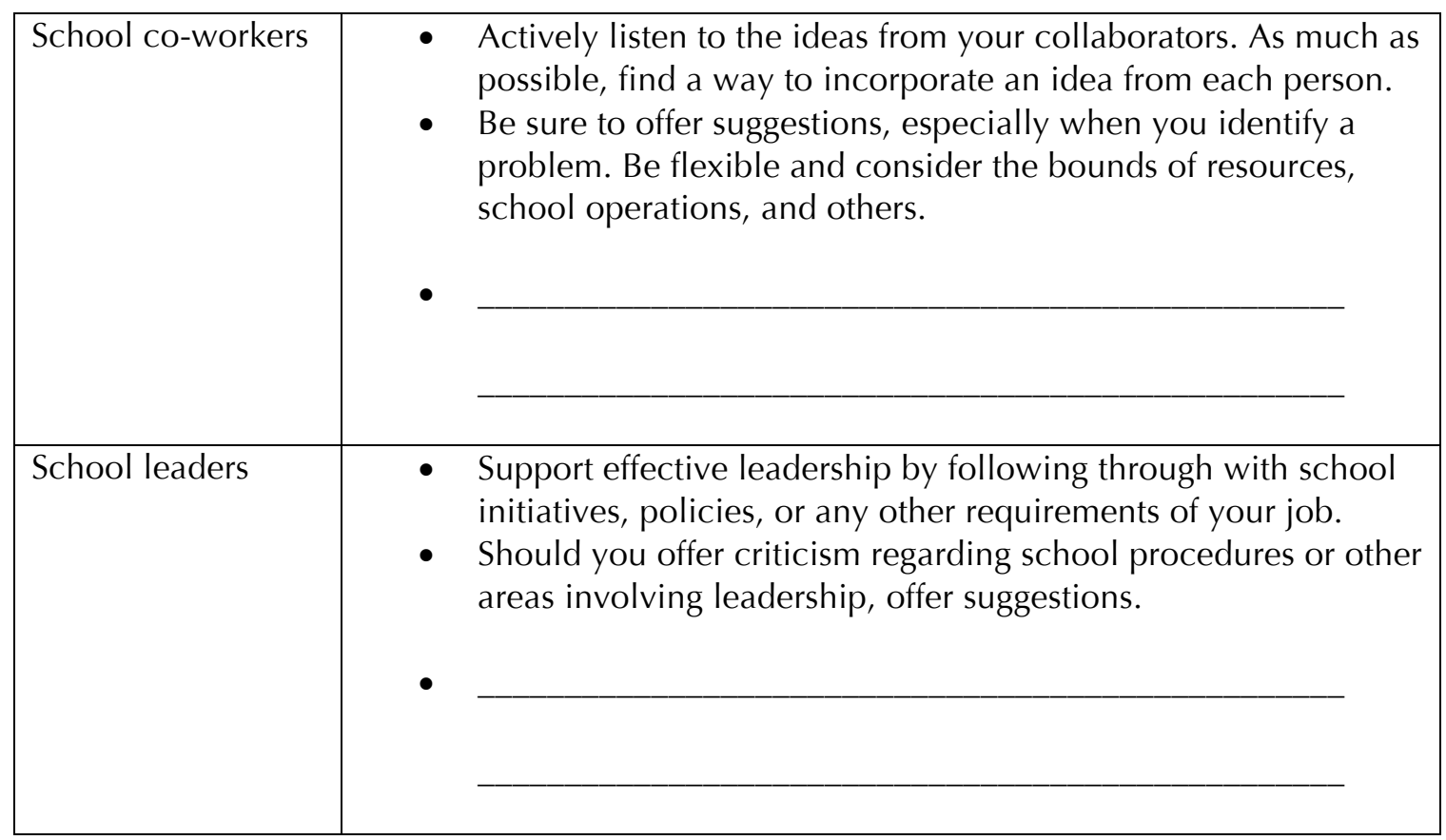

6. In the Heat of the Moment: De-escalation

6a. Check a de-escalation tool you will use to help you if you feel frustrated during the school day. These are micro-versions of the evidence-based strategies from \#4.

\section{REDIRECTION:}

Breathing

Counting

$(4-2-4 ; 4-7-8)$

Stretching/Imagery

(Yoga; Progressive Muscle Relaxation)

6b. List a de-escalation tool you will use outside of school after a particularly stressful day.

Go ahead and plan for this NOW, so that you aren't left trying to figure this out when you may not be functioning at your best.

Rest:

Recharge:

Reboot: 